\title{
Routine measurement of $d$-dimers on suspected SARS-CoV2-infected patients does not lead to significant increase in radiological investigations
}

\author{
Mikkel Brabrand ${ }^{1,2,3}$ D $\cdot$ Søren Bie Bogh ${ }^{4} \cdot$ Marianne Fløjstrup $^{1,2} \cdot$ John Kellett $^{1} \cdot$ Tim Cooksley $^{5} \cdot$ Christian H. Nickel $^{6}$
}

Received: 12 August 2020 / Accepted: 10 November 2020 / Published online: 2 January 2021

(c) Società Italiana di Medicina Interna (SIMI) 2021

\section{Dear Editor,}

A normal d-dimer has been advocated as a strong predictor for favorable outcome in unselected patients with a medical emergency [1, 2] and patients with nonspecific complaints [3]. However, there is concern that if d-dimer was measured routinely, there would be an inappropriate increase in investigations to rule-out venous thromboembolic disease (VTE), notwithstanding the increased risk of VTE in COVID-19 $[4,5]$. During the current SARS-CoV2 pandemic, 8 out of 22 Danish hospitals have routinely been measuring d-dimer on all patients with suspected SARS-CoV2 infection. This provided an opportunity to explore if this policy resulted in a marked increase in ultrasonography for deep venous thrombosis in the lower extremity, and CT pulmonary angiograms (CTA) and ventilation/perfusion (VQ) scans for pulmonary emboli.

Data were obtained from the Danish National Patient Registry on all hospital visits and procedures nationally for patients 18 years or older for the first 17 weeks of 2020 [6]. Difference-in-differences analyses with negative

Mikkel Brabrand

mikkel.brabrand@rsyd.dk

1 Department of Emergency Medicine, Hospital of South West Jutland, Finsensgade 35, 6700 Esbjerg, Denmark

2 Department of Regional Health Research, University of Southern Denmark, Odense, Denmark

3 Department of Emergency Medicine, Odense University Hospital, Odense, Denmark

4 Odense Patient Exploratory Network (OPEN), University of Southern Denmark and Odense University Hospital, Odense, Denmark

5 Department of Acute Medicine, University Hospital of South Manchester, Manchester, UK

6 Emergency Department, University Hospital Basel, Basel, Switzerland binomial regression models were used to determine if the incidence rate ratios of VTE investigations changed after routine d-dimer measurement was introduced. These analyses accounted for heterogeneity between hospitals and were adjusted for whether they were performed during the pandemic, sex, age, Charlson co-morbidity index, and suspected SARS-CoV2 infection (coded at discharge).

The study was approved by the Danish Patient Safety Authority (file no. 20/18426). No informed consent was required.

We included 500,873 hospital visits (Table 1). Crude and adjusted differences in incidence rate ratios for changes in use of lower extremity ultrasound were 0.88 (95\% CI 0.69-1.12) and 0.89 (95\% CI 0.70-1.15), for CTA 0.94 (95\% CI $0.76-1.16)$ and 0.99 (95\% CI 0.80-1.21), and for VQ scan 1.33 (95\% CI 0.69-2.60) and 1.44 (95\%CI 0.74-2.70), respectively.

Our data show that implementing routine measurement of d-dimer on patients suspected of SARS-CoV2 infection did not lead to increased downstream radiological investigations in a population highly representative of those attending Danish emergency departments [7]. There are two potential explanations for this. First, Danish clinicians could be aware of the limitations of d-dimer as stand-alone test and thus only use it is conjunction with a pre-test probability decision rule such as Wells' criteria [8, 9]. Second, d-dimer was reported as part of a routine panel of tests and could have been used as a marker of disease severity and not just as a screening tool for VTE [10].

Yao et al. have shown d-dimer to be a strong prognostic factor in COVID-19 patients in China [11]. We suspect that the same would be the case in our population, but unfortunately, the values of the d-dimer tests were not available to us.

This study's limitation is that the number of d-dimer results reported contemporaneously to the treating physician is unknown. Although, d-dimers were drawn in patients 
Table 1 Demographic information on included hospital visits. Data presented as number (\%)

\begin{tabular}{lll}
\hline & $\begin{array}{l}\text { D-dimer not routinely } \\
\text { measured on hospital level }\end{array}$ & $\begin{array}{l}\text { D-dimer routinely } \\
\text { measured on hospital } \\
\text { level } \\
n=200070\end{array}$ \\
\hline $\begin{array}{l}n=300803 \\
\text { Female }\end{array}$ & $170187(57 \%)$ & $109804(55 \%)$ \\
$18-49$ & $143191(48 \%)$ & $81875(41 \%)$ \\
$50-69$ & $79276(26 \%)$ & $56987(29 \%)$ \\
$70+$ & $78336(26 \%)$ & $61208(31 \%)$ \\
Charlson co-morbidity score & $114815(57 \%)$ \\
0 & $180039(60 \%)$ & $56862(28 \%)$ \\
$1-2$ & $80843(27 \%)$ & $28388(14 \%)$ \\
$3+$ & $39906(13 \%)$ & $17510(9 \%)$ \\
Suspected & $20831(7 \%)$ & \\
SARS- & & \\
CoV2 & & \\
infection & &
\end{tabular}

with suspected SARS-CoV2 infection, the incidence of this condition was very low at the time and, therefore, probably did not influence the response to the d-dimer results. Nevertheless, since there was an increase-albeit insignificant-in the number of VQ scans ordered, some physicians must have at least considered the possibility of venous thromboembolic events, which may have been based on awareness of the increased risk of emboli in COVID-19 patients recently reported [6].

These results suggest that routine measurement of d-dimers on all-comers to an acute unit will probably not result in an unnecessary increase of radiological investigations.

\section{Acknowledgements None.}

Author contributions All authors: study concept and design and critical revision of the manuscript. MB, SBB, MF: acquisition of data. $\mathrm{MB}, \mathrm{SBB}$ : analysis and interpretation. MB: drafting of the manuscript.

Funding No funding was received for conducting this study.

Data availability Not available due to Danish law.

Code availability Stata 15.0.

\section{Compliance with ethical standards}

Conflicts of interest Financial interests: JK is a major shareholder, director, and chief medical officer of Tapa Healthcare DAC. Non-financial interests: None.
Statement of human and animal rights The study was approved by the Danish Patient Safety Administration.

Informed consent Informed consent was not required by Danish law.

\section{References}

1. Lyngholm LE, Nickel CH, Kellett J, Chang S, Cooksley T, Brabrand M (2019) A negative D-dimer identifies patients at low risk of death within 30 days: a prospective observational emergency department cohort study. QJM Int J Med 112(9):675-680

2. ChJ NK, T C, R B, DP H, M B (2016) Combined use of the national early warning score and d-dimer levels to predict 30-day and 365-day mortality in medical patients. Resuscitation 106:49-52

3. Ch N, T K, C K, AS M, N G, R B (2016) Risk stratification using $\mathrm{D}$-dimers in patients presenting to the emergency department with nonspecific complaints. Eur J Intern Med 31:20-24

4. Landi A, De Servi S (2020) The burden of thrombotic complications in critically ill patients with COVID-19: charting the uncharted. Intern Emerg Med 15(5):893-895. https://doi. org/10.1007/s11739-020-02393-1

5. Dubois-Silva Á, Barbagelata-López C, Mena Á, Piñeiro-Parga P, Llinares-García D, Freire-Castro S (2020) Pulmonary embolism and screening for concomitant proximal deep vein thrombosis in noncritically ill hospitalized patients with coronavirus disease 2019. Intern Emerg Med 15(5):865-870. https://doi.org/10.1007/ s11739-020-02416-x

6. S M, Saj S, JL S, V E, L P, HT S (2015) The danish national patient registry: a review of content, data quality, and research potential. Clin Epidemol 7:449-490

7. Fløjstrup M, Bogh SB, Henriksen DP et al (2020) Increasing emergency hospital activity in Denmark, 2005-2016: a nationwide descriptive study. BMJ Open 10(2):e031409. https://doi. org/10.1136/bmjopen-2019-031409

8. Wells PS, Anderson DR, Rodger M, Forgie M, Kearon C, Dreyer J, Kovacs G, Mitchell M, Lewandowski B, Kovacs MJ (2003) Evaluation of D-dimer in the diagnosis of suspected deep-vein thrombosis. N Engl J Med 349(13):1227-1235. https://doi. org/10.1056/NEJMoa023153

9. Wells PS, Anderson DR, Rodger M, Stiell I, Dreyer JF, Barnes D, Forgie M, Kovacs G, Ward J, Kovacs MJ (2001) Excluding pulmonary embolism at the bedside without diagnostic imaging: management of patients with suspected pulmonary embolism presenting to the emergency department by using a simple clinical model and d-dimer. Ann Intern Med 135(2):98-107. https://doi. org/10.7326/0003-4819-135-2-200107170-00010

10. Nickel CH, Kellett J, Cooksley T, Lyngholm LE, Chang S, Imfeld S, Bingisser R, Brabrand M (2020) The diagnoses and outcomes of emergency patients with an elevated d-dimer over the next 90 days. Am J Med. https://doi.org/10.1016/j.amjmed.2020.06.009

11. Yao Y, Cao J, Wang Q, Shi Q, Liu K, Luo Z, Chen X, Chen S, Yu K, Huang Z, Hu B (2020) D-dimer as a biomarker for disease severity and mortality in COVID-19 patients: a case control study. J Intensive Care 8(1):49. https://doi.org/10.1186/s40560-02000466-z

Publisher's Note Springer Nature remains neutral with regard to jurisdictional claims in published maps and institutional affiliations. 